bênh nhân tránh được nhiều di chứng và biến chứng. Việc lựa chọn chất liệu tạo hình phụ thuộc vào từng mức độ tổn thương.

\section{TÀI LIÊU THAM KHẢO}

1. Nguyễn Hoàng Cương và cộng sự (2014). Đánh giá kết quả phẫu thuât tao hình ổ mắt sau chấn thương tại bệnh viện Việt Đức. Kỷ yếu Hội nghi chấn thương chỉnh hình toàn quốc 2014.

2. Sedar Duzgun, Bahar Kayahan Sirkeci (2020). Comparision of post-operative outcoms of graft material used in reconstruction of blow- out fracture. Ulus Travma Acil Cerrahi Derg. 2020; 26(4): 538-544

3. Joseph JM, Glavas IP (2011). Orbital fractures; A reviwiew. Clincal Ophthalmology; 5:95-100.
4. Asmura $S$, Ikada $Y$, Matsunaga $K$, Wada $M$, Isogai $\mathbf{N}$ (2010). Treatment of orbital floor fracture uusing a periosteume polumer complex; Journal of Craniomaxillofacial Surgery; 38:197-203.

5. Courtney DJ, Thomas S, Whitfield PH (2000) Isolated orbital blow-out fracture: Survey and review. BR J Oral Maxillofac Surg; 38:496-503.

6. Simon GJ, Syed HM, McCann JD, Goldberg RA (2009). Early versus late repair of orbital blow-out fracture. Ophthalimic Surg Laser Imaging; 40:141-148.

7. Roth FS et al. (2010). Pearls of orbital trauma management. Serminars in Plastic Surgery; 24(4): 398-409.

8. Whitehouse R. et al (1994). Prediction of enophthalmos by computed tomography after'blow out'orbital fracture. British journal of ophthalmology. 78 (8), pp. 618-620.

\title{
MộT Số KÍCH THƯớC CỦA DÂY CHẰNG CHÉO TRƯớC TRÊN PHIM CHỤP CộNG HƯởNG TỪ
}

\section{TÓM TẮT}

Mục tiêu: Xác định các kích thước của dây chằng chéo trước trên phim chụp cộng hưởng từ. Đối tượng và phương pháp nghiên cứu: nghiên cứu hồi cứu mô tả cắt ngang 40 phim chup công hưởng từ (CHT)khớp gối của bệnh nhân được chẩn đoán không có tổn thương dây chằng chéo trước (DCCT) từ tháng 10/2018- tháng 6/2019, nhằm đưa ra các kích thước củAdcct. Kết quả: các bênh nhân có tuổi trung bình là 31,75 tuổi. Tỷ lệ nam nhiều hơn nữ, gối phải nhiêu hơn gối trái. Đo được chiêuu dài trung bình của DCCT trên mặt phẳng cắt đứng dọc là $36,63 \pm 2,15 \mathrm{~mm}$; trong đó của nam là $37,07 \pm 2,10 \mathrm{~mm}$; của nữ là 35,61 $\pm 2,00 \mathrm{~mm}$; gối phải là $36,76 \pm 2,21 \mathrm{~mm}$; gối trái là $36,39 \pm 2,10 \mathrm{~mm}$. Đường kính trung bìnhtai điểm giữa của DCCT trên mặt cắt đứng dọc là $9,19 \pm 1,84 \mathrm{~mm}$, trong đó của nam là $9,44 \pm 1,85 \mathrm{~mm}$; của nữ là $8,60 \pm 1,73$ mm; gối phải là 9,08 $\pm 2,00$ mm; gối trái là $9,40 \pm 1,57 \mathrm{~mm}$. Kết luận: Qua quá trình nghiên cứu đã đo được chiều dài DCCT và đường kính tại điểm giữa DCCT. So sánh được các kích thước giữa hai giới, hai bên gối.

Từ khóa: Dây chằng chéo trước, cộng hưởng từ

\section{SUMMARY}

STUDY ON MEASUREMANT OF THE ANTERIOR CRUCIATE LIGAMENT (ACL) USING MRI

Purpose: Measurement of the anterior cruciate ligament (ACL) using MRI. Subjects and methods:

*Trường Đại học Điều dưỡng Nam Định

Chịu trách nhiệm chính: Nguyễn Thị Hồng Yến

Email: yendhdd@gmail.com Tel: 0976464219.

Ngày nhân bài: 12/6/2021

Ngày phản biên khoa hoc:5/7/2021

Ngày duyệt bài 26/7/2021

\section{Nguyễn Thị Hồng Yến*}

Restrospectively study 40 cases native anterior cruciate ligament using MRI from October/2018 to June/2019,the research ismeasurement of the anterior cruciate ligament using MRI. Results: The average age is 31,75 . Male prominent, right knee prominent too. In the sagittal plane,the average $A C L$ length was $36,63 \pm 2,15 \mathrm{~mm}$; the average in males were $37,07 \pm$ $2,10 \mathrm{~mm}$; the average in females were $35,61 \pm 2,00$ $\mathrm{mm} ; 36,76 \pm 2,21 \mathrm{~mm}$ in right knee; $36,39 \pm 2,10$ $\mathrm{mm}$ in left knee. In the sagittal plane, the average $\mathrm{ACL}$ width was $9,19 \pm 1,84 \mathrm{~mm}$; the average in males were $9,44 \pm 1,85 \mathrm{~mm}$; the average in females were 8,60 $\pm 1,73 \mathrm{~mm} ; 9,08 \pm 2,00 \mathrm{~mm}$ in right knee; $9,40 \pm$ $1,57 \mathrm{~mm}$ in left knee. Conclusion:the result of the research is the average $A C L$ length and the average $\mathrm{ACL}$ width. They compared between left and right knees and between genders.

Keywords. Anterior cruciate ligament,MRI

\section{I. ĐĂT VẤN ĐỀ}

Dây chằng chéo trước là thành phần quan trọng đảm bảo sự vững chắc về mặt động học theo chiều trước sau của khớp gối. Chấn thương khớp gối là một chấn thương rất hay gặp và tổn thương thường găp nhất trong chấn thương này là tổn thương đứt hay đụng dập DCCT [1]. Phẫu thuât tạo hình dây chằng chéo trước đã trở nên phổ biến và hiện nay được thực hiện hầu hết qua phẫu thuật nội soi. Để đáp ứng đòi hỏi ngày càng cao về hiểu biết giải phẫu DCCT trong chẩn đoán, điều trị và can thiệp phẫu thuật tạo hình lại dây chằng đạt những kết quả tốt, ngày nay chúng còn được quan tâm nghiên cứu dựa trên những kỹ thuật hiện hình ngày càng hiện đại hơn. Chụp cộng hưởng từ là một phương pháp thăm dò không xâm lấn rất ưu việt, cho phép tái 
tạo hình ảnh dây chằng chi tiết và rõ nét với độ phân giải cao[2]. Do đó chúng tôi thực hiện nghiên cứu với mục tiêu là xác định các kích thước của dây chằng chéo trước trên phim chụp cộng hưởng từ.

\section{II. ĐỐI TƯợNG VÀ PHƯƠNG PHÁP NGHIÊN CỨU}

1. Đối tượng nghiên cứu: gồm 40 phim chụp CHT khớp gối người trưởng thành tại Khoa Chẩn đoán hình ảnh bệnh viện Đại học Y Hà Nội từ tháng 10/2018- tháng 6/2019. Các phim chụp được bác sỹ chuyên khoa xác định không có tổn thương trực tiếp hay gián tiếp DCCT, loại trừ nhưng phim chụp bệnh nhân đã được tái tạo DCCT.

2. Phương pháp nghiên cứu: nghiên cứu hồi cứu mô tả cắt ngang trên cơ sở các phim chụp CHT khớp gối để xác định các kích thước giải phẫu của DCCT.

Bảng 1. Chiều dài của DCCT đo trên CHT

BCCT

\begin{tabular}{|c|c|c|c|c|c|}
\hline $\begin{array}{ll}\text { Giới } & \text { DCCT } \\
\end{array}$ & $\mathbf{N}$ & Min & Max & Trung bình & SD \\
\hline Chung & 40 & 32,55 & 41,27 & 36,63 & 2,15 \\
\hline Nam & 28 & 32,55 & 41,27 & 37,07 & 2,10 \\
\hline Nữ & 12 & 33,01 & 38,76 & 35,61 & 2,00 \\
\hline Gối phải & 26 & 32,55 & 41,27 & 36,76 & 2,21 \\
\hline Gối trái & 14 & 32,74 & 39,51 & 36,39 & 2,10 \\
\hline
\end{tabular}

Chiều dài trung bình của DCCT đo ở mặt cắt đứng dọc trên $\mathrm{CHT}$ là $36,63 \pm 2,15 \mathrm{~mm}$, trong đó dài nhất $41,27 \mathrm{~mm}$, ngắn nhất $32,55 \mathrm{~mm}$. Ơ nam giới chiều dài DCCT trung bình là $37,07 \pm$ $2,10 \mathrm{~mm}$, dài nhất $41,27 \mathrm{~mm}$, ngắn nhất $32,55 \mathrm{~mm}$. Ở nữ giới chiêu dài DCCT trung bình là $35,61 \pm 2,00 \mathrm{~mm}$, dài nhất $38,76 \mathrm{~mm}$, ngắn nhất 33,01mm. Chiều dài trung bình của DCCT ở gối phải $36,76 \pm 2,21 \mathrm{~mm}$, trong đó dài nhất $41,27 \mathrm{~mm}$, ngắn nhất $32,55 \mathrm{~mm}$. Chiều dài trung bình của DCCT ở gối trái $36,39 \pm 2,10 \mathrm{~mm}$, trong đó dài nhất $39,51 \mathrm{~mm}$, ngắn nhất $32,74 \mathrm{~mm}$.

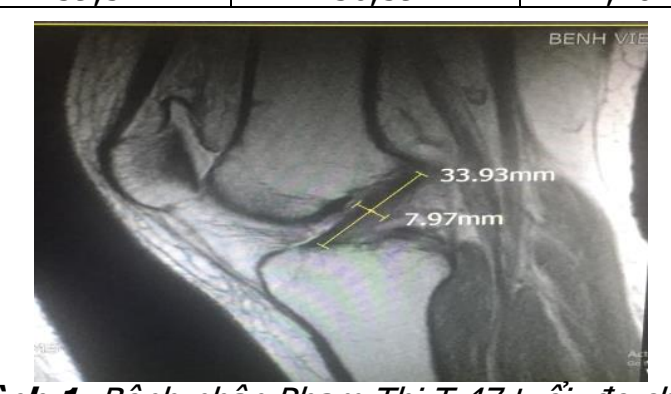

Hình 1. Bệnh nhân Phạm Thị T 47 tuôii, đo chiều dài và đường kính DCCT trên mặt phẳng cắt đứng dọ

\section{KẾT QUẢ NGHIÊN CỨU}

1. Giới: Trong 40 phim khớp gối được nghiên cứu của 40 bệnh nhân thì có 28 nam và chỉ có 12 nữ, tỷ lệ nam/nữ là 7:3.

2. Tuổi: tuổi trung bình của nhóm nghiên cứu 31,75. Trong đó độ tuổi 18 - 30 tuổi là cao nhất gồm 21 người chiểm tỷ lệ 52,5\%, nhón tuổi 31 - 40 có 12 người chiếm $30 \%$, nhóm tuổi 41 50 có 6 người chiếm 15\%, thấp nhất là nhóm bệnh nhân có tuổi 51-60 tuổi chỉ có 1 người chiếm tỷ lệ $2,5 \%$.

3. Vị trí: tỷ lệ gối phải lớn hơn gối trái. Số lượng gối phải 26 chiếm $65 \%$. Số lượng gối trái 14 chiếm 35\%.Ở nam giới số gối phải 19 gối chiếm $67,86 \%$, số gối trái 9 gối chiếm 32,14\%. ở nữ giới gối phải 7 gối chiếm $58,33 \%$, số gối trái 5 gối chiếm 41,67\%.

\section{Chiêuu dài của DCCT}

\section{5. Đường kính của DCCT}

Bảng 2. Đường kính của DCCT đo trên CHT

\begin{tabular}{|c|c|c|c|c|c|}
\hline Giới DCCT & N & Min & Max & Trung bình & SD \\
\hline Chung & 40 & 5,60 & 12,77 & 9,19 & 1,84 \\
\hline Nam & 28 & 5,60 & 12,77 & 9,44 & 1,85 \\
\hline Nữ & 12 & 6,39 & 10,91 & 8,60 & 1,73 \\
\hline Gối phải & 26 & 5,60 & 12,77 & 9,08 & 2,00 \\
\hline Gối trái & 14 & 6,52 & 12,30 & 9,40 & 1,57 \\
\hline
\end{tabular}

Đường kính trung bình tại điểm giữa của DCCT đo ở mặt phẳng đứng dọc trên $\mathrm{CHT}$ là $9,19 \pm 1,84 \mathrm{~mm}$, trong đó dài nhất $12,77 \mathrm{~mm}$, ngắn nhất $5,60 \mathrm{~mm}$. Đường kính trung bình của DCCT ở nam giới $9,44 \pm 1,85 \mathrm{~mm}$, trong đó dài nhất $12,77 \mathrm{~mm}$, ngắn nhất $5,60 \mathrm{~mm}$. Đường kính trung bình của DCCT ở nữ giới 8,60 $\pm 1,73 \mathrm{~mm}$, 


\section{BÀN LUẬN}

Trong nghiên cứu của chúng tôi tỷ lệ nam/nữ là $7 / 3$. Có sự chênh lệch khá lớn này có thể lý giải do nam giới có xu hướng vận động nhiêu hơn nên các chấn thương nói chung và chấn thương gối nói riêng hay gặp ở nam giới nên nhu cầu chụp khớp gối ở nam lớn hơn. Có lẽ còn do sự phân bố tỷ lệ nam/nữ khám bệnh tại Bệnh viện Đại học Y Hà Nội có xu hướng nam cao hớn nữ.

Tuổi trung bình của nhóm nghiên cứu là 31,75 trong đó chủ yếu là nhóm tuổi 18 - 30 tuổi cũng có thể giải thích do xu hướng vận động của nhóm tuổi trẻ là cao hơn nên nhu cầu chụp khớp gối ở nhóm này là lớn hơn.

Về vị trí gối, ở nghiên cứu này gối phải gặp nhiều hơn gối trái. Thực tế ở nhiều nghiên cứu thì chấn thương gặp ở hai bên gối với tỷ lệ tương tự nhau. Và yếu tố chân thuận hay chân không thuận là quan trọng và có ý nghĩa thống kê.

DCCT là cấu trúc quan trọng của khớp gối, trong các chấn thương gối thì tổn thương DCCT lại rất hay gặp. Do vây phẫu thuật tạo hình DCCT đã trở nên phổ biến và hiện nay được thực hiện hầu hết qua phẫu thuật nội soi. Mặc dù giải phẫu của DCCT đã được nghiên cứu từ rất sớm, kỹ lưỡng bằng các kỹ thuật phẫu tích trên xác và được mô tả khá đầy đủ trong các sách giáo khoa giải phẫu kinh điển [3]. Tuy nhiên để đáp ứng đòi hỏi ngày càng cao về hiểu biết giải phẫu trong chẩn đoán, điều trị và can thiệp phẫu thuật tạo hình lại dây chằng đạt những kểt quả tốt hơn chúng vẫn tiếp tục được quan tâm nghiên cứu dựa trên những kỹ thuật hiện hình ngày càng hiện đại hơn.Trong đó kỹ thuật chụp cộng hưởng từ là một phương pháp thăm dò không xâm lấn rất ưu việt, cho phép tái tạo hình ảnh dây chằng chi tiết và rõ nét với độ phân giải cao [2].

Từ nghiên cứu này chúng tôi đã đo đạc được các kích thước của DCCT như sau. Chiều dài trung bình của DCCT đo ở mặt phẳng đứng dọc trên CHTlà 36,63 $\pm 2,15 \mathrm{~mm}$; trong đó dài nhất chúng tôi đo được là $41,27 \mathrm{~mm}$ và ngắn nhất là $32,55 \mathrm{~mm}$. Theo nhiêu tác giả thì chiêu dài trung bình của DCCTnằm trong khoảng từ $37-41 \mathrm{~mm}$ [1], [3]. Tuy nhiên, một số tác giả khác lại công bố kết quả có sự khác biệt một chút, sự khác biệt này là do việc đo đạc thực hiện ở tư thế gấp hay duỗi gối, cẳng chân xoay trong hay ngoài. Trong chụp cộng hưởng từ khớp gối thì tư thế gối cần chụp gấp nhẹ, xoay bàn chân ra ngoài khoảng $10-15^{0}$ so phương thẳng đứng (để quan sát dây chằng chéo trước tốt hơn). Có lẽ vì vậy mà chiêu dài của DCCT hơi ngắn hơn so với các nghiên cứu khác. Theo Mohamed Hamid
Awadelsied cũng đo DCCT trên phim chụp cộng hưởng từ thì chiều dài trung bình của DCCT đo trên mặt cắt đứng dọc là $3,70 \pm 0,42 \mathrm{~cm}$ trong đó dài nhất là $4,4 \mathrm{~cm}$ và ngắn nhất là $3,1 \mathrm{~cm}$ [4]. Như vậy chiếu dài DCCT chúng tôi đo được không có khác biệt nhiều so với nghiên cứu của Mohamed Hamid Awadelsied.

Chiều dài trung bình của DCCT ở nam giới $37,07 \pm 2,10 \mathrm{~mm}$, trong đó dài nhất 41,27 mm, ngắn nhất $32,55 \mathrm{~mm}$. Chiều dài trung bình của DCCT ở nữ giới $35,61 \pm 2,00 \mathrm{~mm}$, trong đó dài nhất $38,76 \mathrm{~mm}$, ngắn nhất $33,01 \mathrm{~mm}$. Kết quả này cũng không có nhiều khác biệt so với của H.P.Wang và cộng sự [5]. Theo H.P.Wang đo được chiêuu dài DCCTđo ở mặt phẳng đứng dọc trên $\mathrm{CHT}$ trung bình ở nam giới là $36,98 \pm 4,12$ $\mathrm{mm}$ và ở nữ giới là $35,80 \pm 4,67 \mathrm{~mm}$. Kết quả của chúng tôi có lớn hơn so với nghiên cứu của Wei Chen và cộng sự (2013) [6]. Theo Wei Chen cũng đo DCCT trên phim chụp cộng hưởng từ nhưng ở măt cắt theo hướng đi của dây chằng thì chiều dài trung bình của DCCT đo được ở nam giới và nữa giới lần lượt $36,45 \pm 1,98$ mm và $34,52 \pm 1,93 \mathrm{~mm}$.

Chiêu dài trung bình của DCCT đo trên $\mathrm{CHT}$ ở gối phải so với gối trái không có sự khác biệt lần lượt là $36,76 \pm 2,21 \mathrm{~mm}$ và $36,39 \pm 2,10 \mathrm{~mm}$. Kểt quả này tương tự như kết quả thu được từ nghiên cứu của H.P.Wang và cộng sự đo được chiều dài của DCCT ở nam và nữ : $36,98 \pm 4,12$ $\mathrm{mm}$ và $35,80 \pm 4,67 \mathrm{~mm}$ [5]. Theo Wei Chen cũng đo DCCT trên phim chụp cộng hưởng từ nhưng ở mă̆t cắt theo hướng đi của dây chằng thì chiều dài trung bình của DCCT đo được ở gối phải và gối trái cũng không có sự khác biệt: $35,31 \pm 1,76 \mathrm{~mm}$ và $35,66 \pm 2,53 \mathrm{~mm}[6]$.

Đường kính trung bình tại điểm giữa của DCCT ở mặt phẳng đứng dọc trên $\mathrm{CHT}$ đo được trong nghiển cứu của chúng tôi là là $9,19 \pm 1,84$ $\mathrm{mm}$, trong đó dài nhất $12,77 \mathrm{~mm}$, ngắn nhất 5,60 $\mathrm{mm}$. Kích thước này nhỏ hơn so với các nghiên cứu được thực hiện trên xác khác (trung bình $11 \mathrm{~mm}$ ) nhưng lại lớn hơn so với nghiên cứu trên cộng hưởng từ của Mohamed Hamid Awadelsied là $0,8 \mathrm{~cm}$ [4]. Đường kính trung bình của DCCT đo trên $\mathrm{CHT}$ ở nam giới lớn hơn ở nữ giới và lần lượt9,44 $\pm 1,85 \mathrm{~mm}$ và $8,60 \pm 1,73 \mathrm{~mm}$. Kết quả này tương tự như ở các nghiên cứu trước. Đường kính trung bình của DCCT đo trên $\mathrm{CHT}$ ở gối phải và ở gối trái không có sự khác biệt là: $9,08 \pm 2,00 \mathrm{~mm}$ và $9,40 \pm 1,57 \mathrm{~mm}$.

\section{KẾT LUÂNN}

Qua quá trình nghiên cứu chúng tôi đo được 
các kích thước của DCCT như sau: chiều dài trung bình của DCCT đo ở mặt phẳng đứng dọc trên $\mathrm{CHT}$ là $36,63 \mathrm{~mm}$; trong đó ở nam dài hơn ở nữ và ở gối phải dài tương đương ở gối trái. Đường kính trung bình tại điểm giữa của DCCT đo ở mă̆t phẳng đứng dọc trên $\mathrm{CHT}$ là 9,19mm; trong đó ở nam đường kính lớn hơn ở nữ và ở gối trái đường kính tương đương gối phải.

\section{TÀI LIẸU THAM KHẢO}

1. Zantop T, Petersen C.W and Fu F.H. (2005). Anatomy of the Anterior Cruciate Ligament. Oper Tech Orthop. 15, pp $20-28$.

2. Nacey NC, Geeslin MG, Miller GW, Pierce JL. (2017). Magnetic resonance imaging of the knee: An overview and update of conventional and state of the art imaging. J Magn Reson Imaging. 45(5), pp 1257-1275

3. Girgis FG, Marshall JL, Monajem A. (1975). The cruciate ligaments of the knee joint. Anatomical, functional and experimental analysis. Clin Orthop Relat Res. (106), pp 216-231.

4. Mohamed Hamid Awadelsied. (2015). Radiological Study of Anterior Cruciate Ligament of the Knee Joint in Adult Human and its Surgical Implication. Universal Journal of Clinical Medicine. Vol. 3(1), pp $1-5$.

5. Wang HP, Cui HK, Yue W, et al.(2015). Determination of patellar ligament and anterior cruciate ligament geometry using MRI. Genet Mol Res.14(4), pp 12352-61.

6. Wei $C$, Bing $X$, Guo-Hong $Z u$, et al. (2013). Oblique coronal view of the ACL double-bundle: Comparison of the Chinese Visible Human dataset and low-field MRI. Exp Ther Med. 6(2), pp 606 - 610.

\section{DỰ ĐOÁN NGUY CƠ MẮC BÊNNH TIM MACH TRONG 10 NĂM THEO THANG ĐIỂM FRAMINGHAM Ở BÊ̂NH NHẦN ĐÁI THÁO ĐƯỜNG TUÝP 2}

\section{Vũ Vân Nga', Hà Thị Thu Thương ${ }^{1}$, Đỗ Thị Quỳnh ${ }^{1}$, Đinh Thị Mỹ Dung², Nguyễn Thị Bình Minh², Nguyễn Thị Lan Anh ${ }^{2}$, Lê Ngọc Thành ${ }^{1,2}$, Vũ Thị Thơm ${ }^{1}$ \\ SUMMARY \\ PREDICT THE RISK-10 YEARS OF CARDIOVASCULAR DISEASE ACCORDING TO FRAMINGHAM RISK SCORE IN TYPE 2 DIABETES MELLITUS PATIENTS}

\section{TÓM TẮT}

Đái tháo đường (ĐTĐ) tuýp 2 là một trong những căn bệnh có xu hướng ngày càng tăng với nhiều biến chứng nguy hiểm, trong đó có nguy cơ gia tăng các tổn thương hê tim mạch. Ước tính khoảng $75 \%$ bênh nhân ĐTĐ tuýp 2 tử vong do hậu quả của các bệnh tim mạch. Tuy nhiên, ở Việt Nam chưa có nhiều nghiên cứu đánh giá nguy cơ mắc bệnh tim mạch trong 10 năm theo thang điểm Framingham (Framingham Risk Score - FRS) ở bệnh nhân ĐTĐ tuýp 2. Để dự đoán nguy cơ mắc bênh tim mạch trong 10 năm và các yếu tố liên quan đến tình trạng này, chúng tôi tiến hành nghiên cứu theo phương pháp mô tả, cắt ngang trên 139 bệnh nhân (62 nam và 77 nữ) ĐTĐ tuýp 2 , có độ tuổi trung bình $66,31 \pm 8,88$, cho thây chủ yếu các bệnh nhân thuộc nhóm nguy cơ rất cao $(41,7 \%)$, nguy cơ cao $(17,3 \%)$, nguy cơ trung bình $(20,9 \%)$ và nguy cơ thấp $(20,1 \%)$. Nguy cơ mắc bệnh tim mach cao hơn ở bệnh nhân nam, trên 60 tuổi, chỉ số khối cơ thể cao, có tình trạng rối loạn lipid máu. Với bệnh nhân ĐTĐ tuýp 2 kèm theo tăng huyết áp có khả nẳng làm tăng nguy cơ ở mức rấtcao lên 10,784 lần.

Tư khóa: Đái tháo đường tuýp 2, bệnh tim mạch, thang điểm Framingham.

${ }^{1}$ Trường ĐH Y Dược-Đại học Quốc gia HN

${ }^{2} B$ ệnh viện E Hà Nội

Chịu trách nhiệm chính: Vũ Thị Thơm

Email: thomtbk5\%gmail.com

Ngày nhận bài: 24/5/2021

Ngày phản biện khoa học: 21/6/2021

Ngày duyệt bài: 15/7/2021
Type 2 diabetes is rapidly increasing rate diseases with many dangerous complications, including an increased risk of blood vessel damage. It was estimated that 75\% type 2 diabetic patients died as a result of cardiovascular diseases. However, in Vietnam, there have not been many studies evaluating the risk of cardiovascular disease in the next 10 years according to the Framingham Risk Score (FRS) in patients with type 2 diabetes. To predict the risk of cardiovascular disease in type 2 diabetic patients in the next 10 years and the factors related to this condition, we conducted a descriptive, cross-sectional study on 139 patients (62 men and 77 women) with type 2 diabetes, with an average age of $66.31 \pm 8.88$, showing that almost patients in very high risk $(41.7 \%)$, high risk $(17.3 \%)$, moderate risk $(20.9 \%)$ and low risk (20.1\%). The risk of caridovascular disease is higher in male patients, over 60 years old with high body mass index, with dyslipidemia. For patients with type 2 diabetes and hypertension, the risk of cardiovascular disease is increased 10.784 times.

Key words: Type 2 diabetes mellitus, coronary artery disease, Framingham risk score

I. ĐẶT VẤN ĐỀ

Hiện nay, số người mắc đái tháo đường (ĐTĐ) trên thế giới đã tăng gấp khoảng 4 lần 